\title{
A magnitude do aborto por anencefalia: um estudo com médicos
}

\author{
Anencephaly: the magnitude of the judicial authorization \\ among medical doctors in Brazil
}

Debora Diniz ${ }^{1}$ Janaína Penalva ${ }^{1}$ Aníbal Faúndes ${ }^{2}$ Cristião Rosas ${ }^{3}$
${ }^{1}$ Anis - Instituto de Bioética, Direitos HumanoseGênero. Caixa Postal 8011. 70673-970 Brasília DF. anis@anis.org.br

${ }^{2}$ UniversidadeEstadual de Campinas.

${ }^{3}$ Comissão Nacional de Violência Sexual da Federação Brasileira das Associações de Ginecologia e Obstetrícia (Febrasgo).
Abstract This paper describes the magnitude of the medical care for pregnant women with an anencephalic fetus. Anencephaly is an abnormality incompatible with life. The right to abort in this case is under litigation at the Brazilian Supreme Court. This survey was conducted among 1,814 medical doctors, all of them affiliated to the Brazilian Federation of Gynecology and O bstetrics (Febrasgo), corresponding to $12 \%$ of the doctors within this federation. The results show that, in a group of 9,730 women cared by the physi cians over thelast 20 years, $85 \%$ preferred to interrupt pregnancy in case of anencephaly. This fact reveals how common the experience of assist women pregnant with an anencephalic fetus is in health care services, as well as the ethical challenge imposed by the restrictive Brazilian legislation on abortion.

Key words Abortion, Anencephaly, Therapeutic Abortion, Interruption of Pregnancy
Resumo Este artigo tem por objetivo descrever a magnitude da assistência médica em casos de gravidez de feto com anencefalia, por meio de uma pesquisa empírica com médicos. $A$ anencefalia é uma má-formação incompatível com a sobrevi da do feto após o parto. 0 direito à interrupção da gestação nesse caso é tema de ação no Supremo Tribunal Fe deral. Realizou-se uma pesquisa tipo survey com 1.814 médicos, filiados à Federação Brasileira das Associações de Ginecologia e Obstetrícia (Febrasgo) , o que correspondea $12 \%$ do total demédicos da entidade. Os resultados indicam que, em um universo de 9.730 mulheres atendidas pel os médicosnos últimos vinte anos, $85 \%$ preferiram interromper a gestação nesse caso. Esse dado mostra o quanto a assistência médica a mulheres grávidas de fetos com anencefalia é uma experiência cotidiana nos serviços de saúde, bem como o desafio ético imposto pela ilegali dade do procedimento médico de interrupção da gestação nesses casos.

Palavras-chave Aborto, Anencefalia, Antecipação terapêutica do oarto, Interrupção da gestação 


\section{Introdução}

A anencefalia é uma má-formação incompatível com a sobrevida do feto após o partoํ. As causas da anencefalia são variadas, mas a carência de ácido fólico durante a gestação é uma das mais comuns ${ }^{2}$. Não há cura ou tratamento para anencefalia e estima-se que mais da metade dos fetos não sobrevivem à gestaçãa $0^{1}$. O s excludentes deilicitude para 0 aborto no Brasil não prevêem a situação clínica da anencefalia ou de outras más-formações incompatíveis com a vida do feto, o que obriga as mulheres a manter a gestação ou buscar autorização judicial para interrompêla sem risco de punição. Alguns estudos mostram que 0 recurso ao Poder Judiciário para a autorização do aborto em caso de feto incompatível com a vida é um fenômeno que teve início nos anos noventa no Brasil ${ }^{3}$.

Uma ação de anencefalia foi apresentada ao Supremo Tribunal Federal (STF) em 2004, por meio deumaArguição deDescumprimento dePre ceito Fundamental (ADPF), pela Confederação Nacional dos Trabalhadores na Saúde (CNTS), com suporte técnico da Anis - Instituto de Bioética, Direitos Humanos e Gênero ${ }^{4}$. N esse mesmo ano, uma medida liminar concedida pelo STF autorizou que mulheres grávidas de fetos com anencefalia optassem pela interrupção da gestação, assim como protegeu os profissionais de saúde que atuassem em tal procedimento médico ${ }^{5}$. A liminar foi cassada ainda em 2004, mas o mérito da ação não foi julgado até o presente momento ${ }^{6}$, havendo a expectativa dequeo caso seja finalizado em 2009.

Sob a compreensão de que o Código Penal não autoriza 0 aborto em caso de anencefalia no feto, hoje, as mulheres que desejam interromper a gestação não podem fazêlo, a não ser que busquem individual mente autorização judicial. Porém, el as não têm garantias de obter a autorização, afinal, dependem da interpretação que o juiz ou promotor dará a cada caso. Esse quadro de exigência de autorização judicial para o procedimento médico é ainda mais agudo para as mulheres usuárias do Sistema Ú nico de Saúde(SUS), no qual o controle de legalidade do procedimento émaior e, de forma concre ta, constitui condição para o direito à assistência? .

Há uma série de desafios éticos na pesquisa sobre o aborto no Brasil. 0 mais importante éque o cenário de criminalização dificulta a recuperação dos dados, pois a participação em uma pesquisa pode trazer riscos à mulher que realizou um aborto ${ }^{7}$. No caso específico da anencefalia ou de outras más-formações incompatíveis com a sobrevida do feto, algumas pesquisas foram conduzidas com mulheres protegidas por autorização judicial ${ }^{8}$, ao passo que a maioria foi realizada com fontes documentais, como alvarás ou despachos do Ministério Público9,10. Os estudos atestam a permanência do recurso ao Poder Judiciário para a garantia do direito ao aborto, sob a tese de que o procedimento médico não deveria se configurar como aborto tal como especificado pelo Código Penal.

A ADPF apresentada ao STF também se amparou nesse giro argumentativo, comum às ações de cortes locais. 0 objetivo não foi instituir um novo permissivo legal no Código Penal, mas demonstrar que a situação clínica da anencefalia não se enquadraria na determinação penal do crime de aborto. Para que se sustente 0 argumento de aborto como crime contra a vida em potencial do feto, é preciso que haja expectativa de vida extra-uterina, algo inexistente para o feto com anencefalia ${ }^{2}$. Por esse caminho argumentativo, a ação de anencefalia propôs a categoria médica e jurídica de antecipação terapêutica de parto para representar os procedimentos médicos autorizados judicialmente havia uma década no país ${ }^{4}$. Uma vez que a realização do aborto por anencefalia no feto não se enquadraria na definição jurídica de aborto segundo o Código Penal, a ação apresentou um novo conceito médico, posteriormentereconhecido pelo Conselho Federal de M edicina, ao definir o feto com anencefalia como "natimorto cerebral" 11 .

Este artigo verifica a magnitude do fenômeno da assistência médica à mulher grávida de feto com anencefalia, por meio deuma pesquisa empírica com médicos ginecologistas-obstetras filiados à Federação Brasileira das Associações de Ginecologia eO bstetrícia (Febrasgo). Dada a dificuldade de recuperação de dados por meio de consulta aos processos judiciais em tribunais locais de todo o país, os mé dicos são uma fonte alternativa para a representação do fenômeno da garantia judicial e da assistência às mulheres grávidas de feto anencefálico.

\section{Sujeitos e método}

A pesquisa foi realizada com médicos ginecologistas-obstetras filiados à Febrasgo, maior entidade médica no campo da ginecologia e obstetrícia no Brasil. 0 levantamento de dados foi realizado por um survey eletrônico, postado em um endereço específico para a pesquisa durante o mês de setembro de 2008. 0 convite à participação foi enviado pela diretoria da Febrasgo ao banco de endereços da entidade, cujo universo de filiados era de mais de 15.000 médicos. A enquete el etrônica era composta de cinco perguntas, três delas com respostas fechadas do tipo "sim" ou "não" e duas delas com 
respostas abertas do tipo simples (número de mulheres atendidas com gravidez de feto com anencefalia). 0 questionário foi anônimo, o que garantiu o sigilo das informações. Para evitar respostas duplicadas, o site no qual foi depositado o questionário reconhecia o endereço IP do respondentee impedia a dupla entrada do participante.

Em 2008, a Febrasgo contava com mais de 15.000 médicos associados, com representação em todas as cidades do país. Foram enviadas 15.000 mensagens com convite à participação na enquete eletrônica. Destas, 2.500 retornaram por erro de registro do endereço el etrônico ou por inexistência de destinatário. Isso resultou em 12.500 médicos como potenciais participantes da pesquisa. Foram recebidas 1.814 respostas, o que correspondia a $14,5 \%$ do total demédicos que deveriam ter recebido 0 questionário.

Consultou-se os médicos ginecologistas-obstetras sobre sua experiência na assistência da muIher grávida de feto com anencefalia nos últimos vinte anos. 0 marco temporal de vinte anos de registro da memória dos médicos se justifica, uma vez que foi no início dos anos noventa que surgiram os primeiros indícios de autorização judicial para a interrupção da gestação em caso de anencefalia do feto no Brasili3,9.

Há duas fragilidades na recuperação dos dados sobrea magnitude da autorização judicial para o aborto em caso de anencefalia por meio da memória dos médicos. A primeira é que o uso da lembrança como recurso de recuperação da informação pode levar a variações no número de casos atendidos, em particular dado o recorte temporal de vinte anos. A segunda éque, nos serviços públicos desaúde, mais de um médico participa do prénatal de uma mulher, o que pode provocar o múltiplo registro de um mesmo caso. Ou seja, mais de um médico pode recordar-se de ter atendido a mesma mulher grávida de feto com anencefalia.

Somente médicos com experiência prévia de atendimento a mulheres grávidas participaram da pesquisa, tendo sido esteum quesito de exclusão à participação. Evitaram-se perguntas relativas a valores ou crenças sobre 0 aborto, a fim de afastar vieses nas respostas. Duas perguntas procuraram delinear a decisão das mulheres diante do diagnóstico deanencefalia no feto: (1) nosúltimos vinte anos, vocêjá atendeu mulheres grávidas de fetos diagnosticados com anencefalia que desejaram interromper a gestação? e(2) nosúltimos vinteanos, do total de mulheres grávidas de fetos diagnosticados com anencefalia que atendeu, quantas delas conseguiram na justiça a autorização para interromper a gestação? As perguntas incluíam a assis- tência tanto na rede privada quanto na rede pública de saúde.

As enquetes respondidas foram processadas eletronicamenteeinseridas em um banco de dados sem eliminação prévia de registros. A partir desses dados, foram realizadas as análises uni e bivariadas apresentadas na seção de resultados. N ão houve registros inválidos ou intercorrências que prejudicassem o processo de tabulação. A incidência de respostas em cada etapa do fluxo que começava pelo do envio das enquetes e culminava na contabilização de médicos que atenderam mulheres que desejavam interromper a gestação é apresentada na Figura 1.

O projeto de pesquisa foi submetido ao Comitê de Ética em Pesquisa em Ciências Humanas da Universidade de Brasília, tendo sido aprovado em agosto de 2008. Os médicos registraram o consentimento livre e esclarecido eletronicamente, antes de responder às perguntas da enquete.

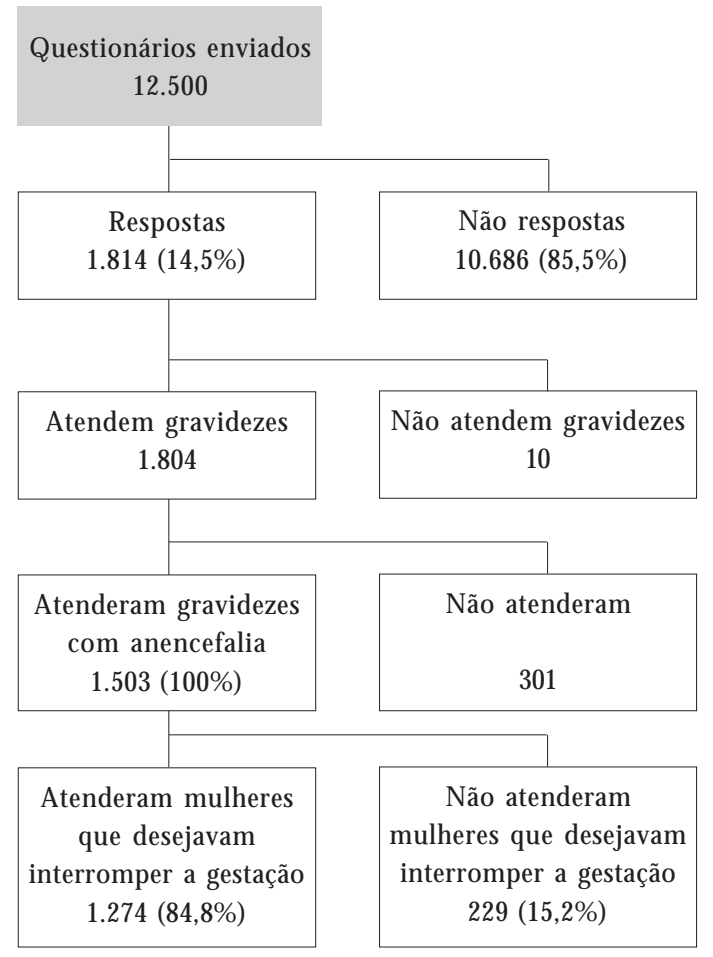

Figura 1. Distribuição das respostas do questionário. 


\section{Resultados ediscussão}

Dos 1.814 médicos ginecologistas-obstetras que responderam à enquete, 1.804 haviam atendido mulheres grávidas nos últimos vinte anos. A grandemaioria desses médicos ( 1.503 de 1.804 ou 83,3\%) tinha atendido pelo menos uma grávida de feto com anencefalia (Figura 1). Como a pesquisa incluiu médicos com pouco tempo de prática obsté trica, essa proporção pode ser ainda maior caso se considere apenas a experiência dos médicos com maior percurso profissional. Isso significa que a prática de assistência à mulher grávida de feto com anencefalia é compartilhada por quase todos os ginecologistas-obstetras duranteo seu curso de vida profissional. Além disso, atender uma grávida com feto anencefálico não éalgo tão excepcional, já que a média foi de 6,5 casos em até vinte anos de prática, para um total de 9.730 grávidas com essa expe riência (Figura 2).

Os dados também permitem verificar que quase $85 \%$ dos médicos que atenderam casos de anencefalia relataram que as mulheres desejavam interromper a gestação (Figura 1). Os resultados revelam que 3.602 mulheres atendidas conseguiram na justiça a autorização para interromper a gravidez. No entanto, os dados não permitem saber quantas das 9.730 mulheres grávidas de fetos com anencefalia teriam declarado o desejo de solicitar a interrupção aos médicos. Como o objetivo da pesquisa era o de explorar a magnitude da assistência médica às mulheres grávidas de fetos com anencefalia e, secundariamente, levantar informações sobre a

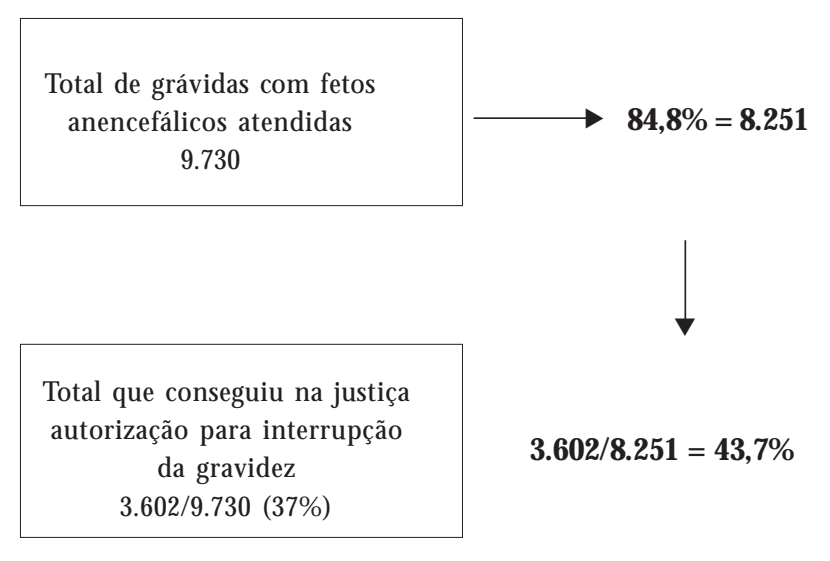

Figura 2. Distribuição das mulheres atendidas que conseguiram autorização para interrupção da gestação. busca por autorização judicial nesses casos, não foram feitas perguntas que pudessem criar receios jurídicos ou éticos, tais como o da realização do procedimento médico sem autorização judicial.

Os dados permitem afirmar que 37\% (3.602 entre 9.730) das mulheres que tiveram gravidez de feto com anencefalia conseguiram autorização judicial para interromper a gestação; porém, não revelam qual é a porcentagem das que desejavam 0 aborto e efetivamente obtiveram essa autorização. Caso se transfira o dado de $84,8 \%$ de médicos que atenderam mulheres que desejavam interromper a gestação às 9.730 mulheres grávidas de fetos com anencefalia, chega-se a uma estimativa de 8.251 mulheres queteriam desejado interromper a gestação, tendo $43,7 \%$ delas (3.602 entre 8.251) obtido autorização para fazê-lo (Figura 2). Esse resultado pode ser interpretado de três maneiras.

Em uma primeira hipótese, isso poderia sugerir que mais da metade das mulheres que desejaram interromper a gestação solicitou, mas não conseguiu autorização judicial. Essa, no entanto, não é uma afirmação possível de se fazer nesta pesquisa e não éo resultado encontrado em estudos qualitativos com decisões judiciais eautorizações do M inistério Público, quedemonstram tendênciafavorável ao aborto em caso de anencefalia no feto $0^{9,12}$.

A segunda possibilidade é que as mulheres não busquem a justiça para interromper a gestação após o diagnóstico deanencefalia no feto, seja por subordinação à ordem penal, seja por desconhecimento do processo judicial ou, ainda, por falta de acesso à justiça. Esse é um caminho interpretativo que necessitaria ser explorado, uma vez que grande parte dos estudosempíricos brasileirosfoi conduzida com mulheres durante o processo judicial, ou seja, após a tomada de decisão pelo aborto ou após sua finalização, no caso dos estudos documentais $5^{9,12}$.

A terceira possibilidade, etal vez a com maiores chances explicativas sobre o fenômeno, é que a autorização judicial não é exigida de todas as muIheres, havendo um grande espaço para a negociação ética protegida pelo segredo médico. Se vier a ser confirmada em estudos futuros, essa hipótese poderá criar oportunidades de outras reflexões no campo ético.

A mais importante reflexão é a que sugere haver uma correlação entre classe social e submissão ao poder judicial para o aborto em caso deanencefalia no Brasil. Em serviços de saúde privados, há uma tendência de que um mesmo médico acompanhe o pré-natal de uma mulher, o que não ocorre em muitos serviços públicos. Essa ruptura no acompanhamento da trajetória reprodutiva dificulta a recuperação do dado da autorização judici- 
al por meio de enquete com médicos que trabaIham em serviço público. Além disso, deve-se considerar a hipótese de que, em alguns serviços privados de assistência pré natal, haja a possibilidade de um pacto de solidariedade entre equipe de saúde e mulheres não condicionar o procedimento médico à autorização judicial. 0 fato éque os estudos empíricos realizados com mulheres que abortaram, especialmente em casos de má-formação fetal, são quase todos conduzidos em serviços públicos de saúde7, em que há maior rigidez quanto à exigência de autorização judicial para 0 acesso à interrupção da gestação.

A via judicial seria um fenômeno das mulheres mais pobres e usuárias dos serviços públicos de saúde, para quem a exigência da autorização judicial seria condição para 0 acesso ao aborto, em razão da rigidez no controle da legalidade nesses contextos. Em geral, os serviços públicos de saúde são locais onde há menor espaço para o sigilo médico e a confidencialidade dos dados, o que dificulta a negociação de escolhas privadas em detrimento da lei. Váriosestudos sobreas consequências dailegalidade do aborto no Brasil já mostraram o quanto a restrição do direito e da assistência para essa prática impõe efeitos mais perversos às mulheres pobres ${ }^{7}$.

\section{Considerações finais}

A Arguição de Descumprimento de Preceito Fundamental (ADPF) deverá ser julgada pelo STF em 2009. Será a primeira vez que a su prema corte brasileira decidirá uma questão de direito reprodutivo, uma tendência crescente às cortes latino-ame- ricanas, como já ocorreu na Argentina e na Colômbia. Por ser um tema rodeado de desafios éticos para a pesquisa, há uma carência de estudos com evidências empíricas sobre o fenômeno do aborto em caso de anencefalia no Brasil. Esta pesquisa, conduzida com médicos ginecologias-obstetras, sinaliza a magnitude do fenômeno médico, jurídico e ético nos últimos vinte anos.

Os resultados mostram que $83,3 \%$ dos médicos ginecologistas-obstetras brasileiros já atenderam mulheres grávidas de fetos com anencefalia e que em torno de $84,8 \%$ dessas mulheres desejaram interromper a gestação. Esse dado indica 0 quanto o fenômeno da gestação de fetos incompatíveis com a vida éuma experiência cotidiana às equipes de saúde no Brasil. 0 reconhecimento do direito ao aborto nesses casos deve ser entendido como uma matéria de ética privada; por isso, muIheres que desejarem manter a gestação ou que optarem pelo aborto serão igualmente protegidas e assistidas pelas equipes de saúde. No entanto, 0 acolhimento às escol has sem interferência do Judiciário deve ser entendido também como uma medida terapêutica, pois transfere o tema da esfera do crime para a das decisões éticas cotidianas à assistência em saúde.

A verdadeira magnitude da autorização judicial para o aborto em caso de anencefalia no feto éainda desconhecida, pois há possibilidades dequenem todos os casos de procedimento médico de aborto tenham sido condicionados à autorização judicial prévia. A pesquisa mostra o quanto o encontro da ética com a justiça e a assistência médica foi um fenômeno crescente para a mediação do desafio do aborto nos últimos vinte anos no Brasil.

\section{Colaboradores}

Todos os autores participaram da fase de elaboração do instrumento erevisão dos dados. D Dinize A Faúndes foram responsáveis pela análise dos dados empíricos. D Diniz foi responsável pela re dação do artigo e os autores, pela revisão dos argumentos. 


\section{Agradecimentos}

A equipe de pesquisa agradece à Federação Brasileira das Associações de Ginecologia e Obstetrícia (Febrasgo) pela gentileza em cooperar com o estudo, informando aos médicos sobre o survey eletrônico, a João N eves pelo gerenciamento do site para o questionário el etrônico e a M árcia Camargo, secretária da Febrasgo, pela permanente atenção durante a execução da pesquisa. Agradece ainda a todos os 1.814 médicos que participaram da pesquisa. Os autores agradecem a leitura e os comentários de M arilena Corrêa

Esta pesquisa foi financiada pela International Women's H ealth Coalition e executada pela U niversidade de Braślia.

\section{Referências}

1. Cunningham FG, Gant N, Leveno K, Gilstrap L, Hauth J, Wenstrom K. Tratado de obstetrícia de Williams. 20aㅡ ed. Rio de Janeiro: Guanabara Koogan; 2000.

2. Swaiman K, Ashwal S. Anencephaly. In: Swaiman K, Ashwal S, editors. Pediatric neurology: principles and practice. Vol. 1. Boston: M osby; 2003. p. 250-251.

3. Gollop TR. Abortamento por anomalia fetal. In: Cavalcante A, Xavier D, organizadoras. Em defesa da vida: aborto e direitos humanos. São Paulo: Católicas pelo Direito de Decidir; 2006. p. 69-80.

4. Barroso LR. ADPF Anencefalia. In: CREMEB. Anencefalia e Supremo Tribunal Federal. Brasília: LetrasLivres; 2004. p. 69-119.

5. Diniz D. Selective abortion in Brazil: the anencephaly case. Dev World Bioeth 2007; 7(2):21-28.

6. Diniz D. Severina torturada. In: Porto $M$, organizadora. Olhares femininos, mulheres brasileiras. São PauIo: X Brasil; 2006. p. 45-54.

7. Brasil. Ministério da Saúde. Secretaria de Ciência, Tecnologia e Insumos Estratégicos. Departamento de Ciência e Tecnologia. 20 anos de pesquisas sobre aborto no Brasil. Brasília: M inistério da Saúde; 2009.

8. Panigassi AP, Simioni C, Nardozza LM M, Abrahão AR. Complicações obstétricas em gestações com feto portador de anomalia incompatível com a sobrevida neonatal. In: Anais do XIII Congresso Paulista de Obstetrícia e Ginecologia; 2008; São Paulo. p. ii.

9. Frigério $M$. Aspectos bioéticos, médicos e jurídicos do abortamento por anomalia fetal grave no Brasil. Rev Bras Ciênc Crim 2003; 11(41):268-329.

10. Diniz D. Quem autoriza o aborto seletivo no Brasil? M édicos, promotores e juízes em cena. Physis 2003; 13(2):251-272.

11. Conselho Federal de M edicina. Resolução $n^{\circ} 1752$, de 8 de setembro de 2004. Autorização ética do uso de órgãos e/ou tecidos de anencéfalos para transplante, mediante autorização prévia dos pais. Braślia: Conselho Federal de Medicina; 2004.

12. Gonçalves TA, Lapa TS. Aborto e religião nos tribunais brasileiros. São Paulo: Instituto para a Promoção da Equidade; 2008.

Artigo apresentado em 17/04/2009

Aprovado em 20/05/2009 